\title{
Fine description of sedimentary system in Wuerxun Sag of Hailaer Basin
}

\author{
ZHOU Yue ${ }^{1}$, GAO Geng ${ }^{1}$, WANG Duanyang ${ }^{1}$, YANG Xu ${ }^{1}$ \\ ${ }^{1}$ Exploration and Development Research Institute of Daqing Oil Field Co. Ltd, Daqing City, Heilongjiang Province, 163712,China
}

\begin{abstract}
Wuerxun depression is one of the depressions with great exploration potential in Hailaer Basin and has submitted large-scale reserves. At present, it has entered the stage of fine exploration, and the exploration object has changed from structural reservoir to lithologic reservoir exploration. The remaining targets are mainly concentrated in the trough and surrounding areas, with strong concealment and difficult to identify. Fine identification of sand bodies, genesis, types and distribution of sedimentary fans are one of the key factors restricting oil and gas exploration. Based on core observation and genetic mechanism, three sedimentary facies models of Braided River Delta, fan delta and sublacustrine fan are established. In this paper, the method of "sequence control, cycle correlation and hierarchical closure" is used to fine characterize the fan delta sedimentary system in this area, which lays a foundation for the study of sedimentary microfacies of subdivision layers, optimization of lithologic reservoir targets and guidance of oil and gas exploration deployment.
\end{abstract}

\section{1 preface}

Wuerxun depression is one of the main oil-rich sags in Hailaer basin, with an area of $1850 \mathrm{~km}^{2}$ and great resource potential. Wuerxun Sag has experienced multiple tectonic activities and complex structural fault system. Under this tectonic background, the strata from Tongbomiao formation to Damoguaihe Formation are mainly characterized by multi provenance, short provenance, near provenance, rapid phase change and rapid sediment unloading. In the same trough, multiple fan bodies are superimposed with each other and the spatial relationship is complex, forming various fan bodies such as impact fan, fan Delta, sublacustrine fan, nearshore subaqueous fan and far shore subaqueous fan. The sedimentary period of Tongbomiao formation is in the early stage of fault depression, with close provenance and fast sedimentation rate. Small depressions are scattered, and small protuberances in the depression provide sporadic provenance. In the early and middle stage of Nantun Formation deposition, the fault depression developed at the peak period. The lake developed and the provenance mainly came from the periphery of the depression. In the later stage, the distribution of lake water area was the most extensive, resulting in the development of coarse clastic materials. In the late stage of Nantun Formation deposition, the provenance around the lake inundation developed. In the same trough, the multi-stage fan bodies overlapped each other, and various influencing factors restricted each other, and the main controlling factors were not clear. Therefore, the distribution, identification and characterization of fan bodies became the necessary means for further searching for oil and gas.

\section{Fan delta sedimentary system}

Fan delta is a depositional system directly pushed into Lake Basin by alluvial fan. It is usually formed on the steep side of short axis of depression, with large terrain elevation difference and close to provenance. It is a coarse-grained sedimentary system generally developed under the background of growth fault. It reflects the lithologic characteristics of shallow water and is mainly formed by traction flow.In the fan delta plain, massive beddings and conglomerates are developed, and the scour surface, progressive bedding and cross bedding are developed in the front of the fan delta; parallel bedding and deformation structures are developed in the front fan delta; and the typical three-layer structure is found in the sedimentary sequence. The front delta is composed of grey mudstone and argillaceous siltstone with reverse grain sequence; the front edge is positive grain sequence glutenite intercalated with gray mudstone and siltstone; the plain is positive grain sequence glutenite and purplish red and gray mudstone(Fig. 1). The transport mechanism is mainly caused by gravity flow and tractive flow, and the grain size curve is mainly of two-stage and two-stage transitional types; on the seismic section, it is characterized by "s" shaped or wedge-shaped progradation seismic reflection on the seismic section, converging towards the lake basin (Fig. 2). Its subfacies are mainly composed of fan delta plain, fan delta front and front fan delta, with steep slope faults. There are two

\footnotetext{
* Corresponding author: dqzhouyue@petrochina.com.cn
} 
types of slope break belt, mainly developed in Wuxi fault terrace zone and Wubei steep slope zone.

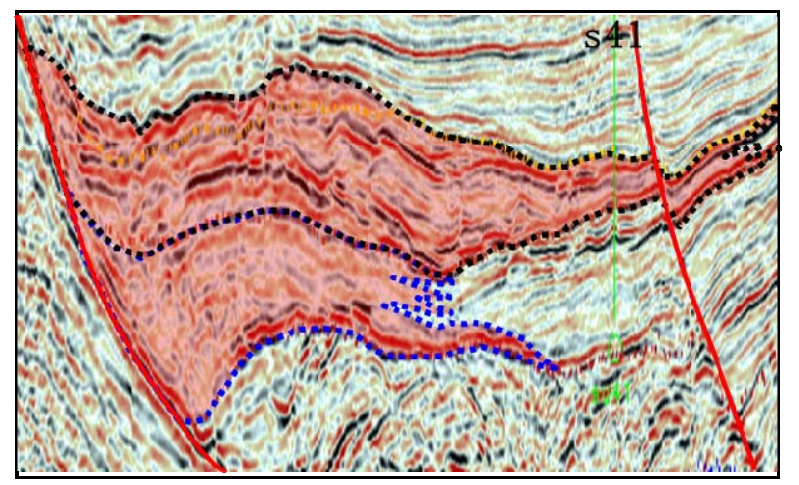

Fig. 1. Seismic reflection characteristics of fan delta sedimentary system

\subsection{Fan delta plain subfacies}

The fan delta plain is the onshore part of the fan delta, which is divided into three sedimentary microfacies: distributary channel, inter channel and natural dike. The sedimentary cycles are mainly composed of several coarse to medium fine positive cycles with a small amount of red, variegated and greyish green fine sandstones, siltstones and argillaceous siltstones. The common channel cross bedding in sandstones has scouring surface. The logging curves are bell shaped or box shaped, sandwiched or serrated.

\subsection{Fan delta front subfacies}

Fan delta front deposit is the main body of fan delta deposit, and its lithology is mainly gray, gray black conglomerate, conglomerate, coarse sandstone and thin gray mudstone. Generally, it has the characteristics of normal cycle with coarse in the lower part and fine in the upper part. It is poor to medium in roundness and sorting. Large or small trough cross bedding, wavy cross bedding and deformation bedding are developed. The bottom has obvious scouring characteristics. The main microfacies are underwater distributary channel, underwater distributary channel, mouth bar and front sheet sand.

\subsection{Fan delta subfacies}

The front fan delta deposits are developed at the farthest end of the offshore fan delta, and it is difficult for the provenance supply to reach the area directly. It is mainly composed of suspended still water sediments, mainly composed of interbedded gray green, gray black mudstone and argillaceous siltstone. Silty lens interlayers are common in this area. There are abundant Ostracoda and Ostracoda fossils. The deep and shallow lateral curve is straight. It is difficult to distinguish the pre delta deposits from the lacustrine dark mudstones because of the narrow distribution of the deposits. Coarse sand bodies are often found in the two, which are the origin of underwater gravity flow.

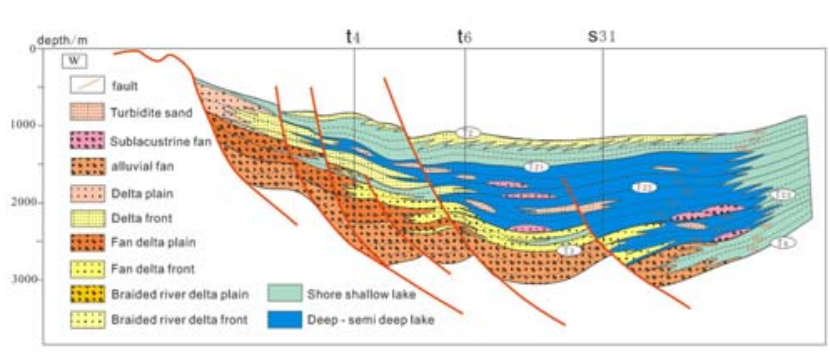

(a The fault-step slope break zone and sedimentary model of the North Subconcave steep slope of Wuerxun)

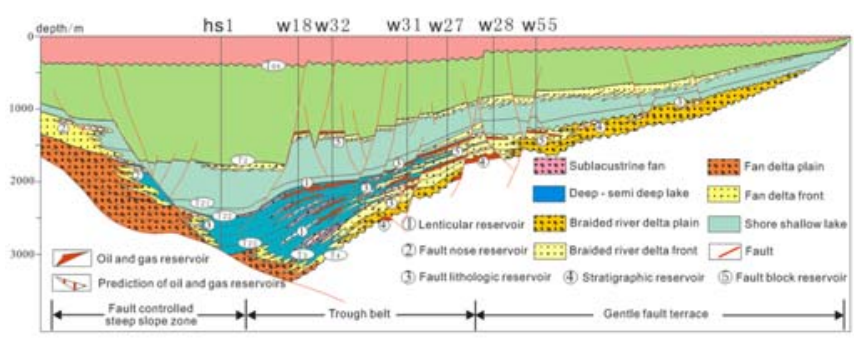

(b The fault-step slope break zone and sedimentary model of the South Subconcave steep slope of Wuerxun)

Fig. 2. Development model of fan delta sedimentary sand body

\section{Sedimentary system of Braided River Delta}

The braided river delta sand body is a shallow water delta formed by braided river entering the lake, which belongs to coarse-grained delta with the same characteristics as fan delta. It is mostly distributed on the side of short axis gentle slope, but the required sedimentary topography and slope are generally slower than that of fan delta; massive bedding sandstone is developed in the braided river delta plain, and the retained sediment erosion structure at the bottom can be seen; the scouring surface and gradient are developed in the front of Braided River Delta The main sedimentary sequence of the braided river delta is the interbedding of dark mudstone and argillaceous siltstone; the front edge is composed of normal grain sequence glutenite with gray mudstone and siltstone; the plain is composed of normal grain sequence glutenite and purplish red and gray mudstone; the sediment is reflected as the transport mechanism of traction current, the probability grain size curve is a three - stage type of traction flow, the particle size of relative sediment is fine and the separation is good, it is characterized by en echelon seismic reflection on the seismic section and its internal progradation reflection is obvious.

\subsection{Braided river delta plain subfacies}

The braided river delta plain subfacies are the onshore part of delta deposits and the top deposits of braided river delta deposits. It is composed of mudstone, siltstone and sandstone interbedding, with large-scale trough cross bedding, and vertically it is a positive cycle with upward thinning lithology. The seismic section is 
characterized by high amplitude reflection, good continuity, subparallel or parallel reflection. The microfacies of discriminative channel, distributary channel and natural dike are mainly developed.

\subsection{Braided river delta front subfacies}

The subfacies of braided river delta front are mainly composed of gray fine sandstone, coarse sandstone and siltstone, with mudstone locally. On the seismic section, it is characterized by oblique progradation along the flow direction, with good continuity and medium high amplitude reflection characteristics. The front facies zone is the main body of Braided River Delta, which can be subdivided into underwater distributary channel, underwater distributary channel, estuary bar, sheet sand and distal bar.

\subsection{Braided river delta subfacies}

The braided river delta subfacies are the bottom sediments of Braided River Delta, which appear at the bottom of the delta complex cycle, with thin thickness and fine lithology. The lithology is mainly composed of dark gray and gray mudstone and silty mudstone, intercalated with extremely thin layer of argillaceous siltstone and siltstone, with horizontal bedding generally developed. The electrical logging curve shows low resistance tooth shape, and it is weak amplitude and low medium continuous reflection in seismic section. It is difficult to distinguish them from shallow lacustrine mudstones, but they can be distinguished by the fact that they are located at the bottom of the delta cycle and can be coarsened upward together with distal bar and mouth bar.

\section{Sedimentary system of sublacustrine fan}

Gravity flow of sublacustrine fan system carries a large amount of clastic materials rapidly accumulated in the deep lake area, forming fan-shaped sandstone body, which is often sandwiched in dark mudstone in the form of huge lens (Walker, 1978), which has a certain scale and a wide range of deep-water sedimentary areas.

\subsection{Inner fan}

The inner fan can be divided into two microfacies: the main channel and the outer channel. The main channel is the main body of the inner fan, and the main channel microfacies debris flow (debris flow) is the main channel. The lithology is mainly composed of matrix support without internal structure and conglomerate or sandstone supported by graded bedding particles. The matrix supported conglomerate or sandstone shows massive rhythm, while the grain supported conglomerate or sandstone shows positive rhythm or reverse rhythm. The conglomerate is poorly sorted, and the composition of gravel is complex. The gravel of common magmatic rock, metamorphic rock and torn mud gravel float upright in the conglomerate.

\subsection{Middle fan}

The middle fan is characterized by relatively welldeveloped braided channels, and its flanks pinch out rapidly towards deeper Lake mudstone.

The lithology of braided channel is massive thick sandy conglomerate and gravelly sandstone intercalated with dark gray mudstone. The SP curve is bell shaped and box shaped negative anomaly combination, and the apparent resistivity curve is comb shaped and massive high resistivity. The gravels are often mixed in size, and the roundness is mainly in the form of sub circle and sub edge. The separation is poor. The sedimentary structures are mainly composed of massive bedding, positive progressive bedding and superimposed progressive bedding, with parallel bedding, tabular cross bedding and small cross bedding locally.

\subsection{External fan}

The outer fan is located at the most front edge of the sublacustrine fan, adjacent to the normal deep-water lake. Due to no water channel limitation, the thin-layer turbidite distributed horizontally and the mudstone of deep lake facies were deposited alternately, and distributed in a belt around the fan body. The lithology is mainly siltstone and mudstone, and thin-layer fine sandstone is occasionally seen. The outer fan shows low amplitude toothing on the logging curve. Ripple bedding, deformation bedding and horizontal bedding are common, and clastic vein, heavy load model and sand ball structure can be found.

\section{Lacustrine sedimentary system}

The lacustrine depositional system can be divided into two subfacies: shore shallow lake, deep-semi deep lake and various microfacies developed respectively.

\subsection{Deep-semi deep lake sedimentary subfacies}

The environment water of deep-semi deep lake is still or even stagnant. The seismic reflection is mostly parallel, sub parallel sheet reflection and wave random Hill reflection. In the vertical direction, large-scale deep lake and semi deep lake sedimentary environment are developed in the south-1 member and DA-1 member, and a large set of dark mudstone is deposited. The mud microfacies of deep lake and semi deep lake are mainly gray, gray black and black mudstone, and the electrical logging curve is micro toothed with low amplitude.

\subsection{Shore shallow lake subfacies}

Under ideal conditions, the littoral and shallow lake subfacies are usually distributed in the periphery of the deep lake semi deep lake subfacies in a circular 
distribution, and the actual distribution characteristics are usually more complex. Vertically, the shore shallow lake subfacies can be superimposed with various sedimentary facies.

Its sedimentary environment is characterized by its nearness to the shore, shallow water level, acceptance of coarse clastic materials from the lakeshore, complex hydrodynamic conditions, and strong remolding effect on the sediment by the scouring and washing of rippling waves and backflow. On the seismic section, the shore shallow lake deposits are of medium and weak amplitude or variable amplitude medium and low continuous reflection structure, and the seismic reflection generally takes the shape of sheet or wedge. Shore shallow lake subfacies can develop sandstone reservoir and mudstone cap rock with good performance.

\section{Conclusion}

Through the fine description of the sedimentary system in this area, the study of sedimentary microfacies of subdivision layer, optimization of lithologic reservoir target and guidance of oil and gas exploration deployment are laid. Fine characterization of fan body under subdivision layer is studied. Multi stage fan identification and reservoir prediction technology are applied to fine depict the distribution characteristics of favorable oil-bearing fan body. Stratigraphic subdivision and fine division correlation, fine structural interpretation and trap identification, sedimentary microfacies research and plane prediction, fan body identification and reservoir fine prediction, lithologic reservoir target optimization and evaluation are carried out to establish isochronous layer in Wuerxun Sag Sequence stratigraphic framework, study sedimentary system and reservoir characteristics in fine geological cell frame, depict geological body morphology, predict favorable reservoir distribution, discuss lithologic reservoir forming conditions and hydrocarbon accumulation law, optimize favorable areas, search and select favorable exploration targets in favorable areas, and guide the next exploration deployment of Wuerxun Sag.

\section{References}

1. Zeng Hongliu 2014 Thin-Bed Prediction by Geomorphology-Constrainer Waveform Analysis(Chinese:Society of Exploration Geophysics)2014:pp1395-1399

2. Li Zhenzhou, Yang Xiaochuan, Gong Pengyu, etc. 2015 Application of seismic single frequency body in identification of small faults in Lunnan Oilfield(Chinese:Petroleum Geology and Engineering) (06) : pp92-94

3. Liu Jingjing, Liu Zhen, Qi Yu, etc. 2016 Prediction of deep-water reservoir by seiemic frequency division technology(Chinese:Acta Petrolei Sinica) 37 (1) : pp80-87

4. Yu Haoye, Zhao Weijun, Ou Yaping, etc. 2016
Petroleum Reservoir Characteristics and Favorable Exploration Areas in Faulted Slope-Break Zone of Bozingen Graben, Kazakhstan(Chinese:Xinjiang Petroleum Geology)37 (4) : pp494-498

5. Zhao Xianzheng, Zhou Lihong, $\mathrm{Pu}$ Xiugang, etc. 2017 Hydrocarbon enrichment theory and exploration practice in the slope of fault lake basin a case study of Paleogene in Huanghua depression(Chinese:China Petroleum Exploration)22 (2) : pp13-24 